\title{
Pension Systems, Demographic Change and the Stock Market
}

\author{
Marten Hillebrand \\ New York, Springer Press, 2008. \\ ISBN: 978-3540779711, \$89.95, 176 pages.
}

\author{
Marc-André Letendre \\ McMaster University \\ letendre@mcmaster.ca
}

Confronted with decreased fertility rates and increased life expectancy, several developed countries face a significant demographic challenge over the next 50 years as the number of retirees in those countries inevitably grows much faster than the number of workers. This will lead to a dramatic increase in the dependency ratio - defined as the ratio of the number of pensioners to workers - and will have significant political, economic, and social implications. One economic issue that receives a great deal of attention is how public pension systems will cope during the transition period. In the case of a "pay-as-you-go" pension system, the government collects contributions from workers and transfers these revenues to retirees. An increase in the dependency ratio means that the pension system collects less total contributions and has to divide them among a larger number of retirees, which means less pension income for retirees. This evidently has implications for the well being of these individuals. Changes to the parameters of the pension system like the contribution rate or the retirement age also have implications that must be studied carefully.

The book Pension Systems, Demographic Change, and the Stock Market by Marten Hillebrand studies the implications of the looming demographic transition on pension systems, the stock market and individual welfare. The book is organized in two parts. In the first part, the author lays out an equilibrium macroeconomic model of the overlapping generation type. In the model, a new generation of individuals/consumers with finite life span are born. These consumers work for a number of periods before they enter their retirement years. Therefore, in each period workers and retirees coexist, which is the kind of demographic structure appropriate for the study of the demographic transition of interest. A pay-as-you-go pension 
system is included in the model. Consumers can trade one-period bonds as well as shares in firms to smooth out their consumption over time. Goods are produced by firms who hire workers and issue bonds to draw the resources necessary to accumulate physical capital used in the production process. Firms face a random production shock which makes the model stochastic. Since this is an equilibrium model, all prices (wage rate, stock prices, and return on bonds) are endogenously determined in the model by equating demand and supply on all markets. An equilibrium model such as this offers the advantage that since asset prices are determined endogenously, it allows for the real side of the economy to influence the financial side and vice versa. Not all models in this literature make asset prices endogenous and allow for feedback effects between the real and financial sectors. This would not matter if the interactions between the two sectors proved irrelevant for the questions studied, but as discussed below, this is not the case.

The author initially lays out the model in fairly general terms, and then subsequently specializes it by making some assumptions about functional forms (e.g., logarithmic utility, Cobb-Douglas production function, etc.) to allow the derivation of closed-form decision rules. Still, the complexity of the model does not allow the author to fully solve it analytically, and as a result, he spends the second part of the book conducting a numerical analysis. The first part of the book is technical since carefully laying out such a complex model and characterizing demand functions in general terms makes using heavy mathematics unavoidable. The fact that the book is well written and that summaries of key equations and results appear regularly help the reader identify the most important material.

While there is a tendency for equilibrium macroeconomic models to include rational expectations where agents formulating forecasts of the future are aware of the distributions from which the variables to forecast are drawn, Hillebrand's model does not entirely follow this lead. For example, firms form point forecasts of the future values of the wage rate using a naive forecasting rule where the expected wage rate next period is equal to the wage rate in the current period. Naive forecasting rules are also used by consumers to predict future noncapital income and bond returns. Those who are firm believers in rational expectations may perceive this as a weakness. A clear advantage of the assumed expectations structure is that it allows the author to dig into the vast literature on consumption/savings decisions and on portfolio allocation. For example, the closed-form solution of the consumption function clearly resembles that derived by Hakansson (1970).

The second part of the book uses numerical simulations to study how the model reacts to a sharp increase in the dependency ratio, to changes in the pension contribution rate, and to changes in the retirement age. The first set of experiments where the contribution rate is varied are actually done 
in a stationary population context. This is useful since it gives the reader a sense of how the artificial economy works. The simulation results are presented in graphs and tables that are easy to read and interpret. The author documents how the mean and variance of variables like the capital stock, bond returns, stock prices, wage rate, investment in bonds and investment in stocks depend on the size of the pension contribution rate. A nice aspect of using a model with microeconomic foundations is that it allows the author to calculate the consumers' expected utility (a measure of the well being of consumers) as a function of the pension contribution rate.

The second set of experiments are of great interest since they are concerned with the effects of the demographic transition. The change in the demographic structure assumed in the numerical analysis is designed to roughly mimic the transition Germany will face over the next fifty years. The results of the first experiment where the government leaves the parameters of the pension system unchanged are chilling: The stock market plunges dramatically as do output and the capital stock. Not surprisingly, the consumers alive during the transition suffer large losses of welfare. The behaviour of the stock market in response to the demographic transition shows the importance of having a model where the real and financial sectors are connected. The wealth that vanishes as a result of the stock market crash is certainly an important factor driving down consumption and utility of those alive in the transition period. It seems legitimate to wonder how the drop in consumption and utility could be mitigated by workers deciding to work longer hours to increase their labour income and finance consumption. This is not allowed in the model since there is no labour/leisure choice (a worker supplies his entire time endowment to the labour market). If consumers were allowed to choose how many hours they work and leisure were a normal good, the stock market meltdown would make them work more. This would help pay for more consumption but would also reduce leisure so that in the abstract, it not possible to tell whether this would change the individual lifetime utility significantly.

In a final set of experiments, the author looks for ways in which the contribution rate and the retirement age could be changed to alleviate the welfare loss that the demographic transition will impose on consumers. $\mathrm{He}$ considers dramatic and gradual decreases in the contribution rate, increases in the contribution rate, and an increase of the retirement age. The simulation results suggest that the policy to follow to prevent welfare losses for those alive during the demographic transition is a combination of higher retirement age and gradual reduction in the contribution rate.

The book is well organized and well written, even though the author could have provided a little more economic insight to help the reader understand the numerical analysis. 
Readers who are not mathematically inclined will find the first part of the book quite challenging. Readers with an interest in the economic consequences of the looming demographic transition for pension systems and the stock market will find this book very interesting even if they are not doing active research in this area. By reading this book, I certainly learned a lot about the technical aspects of macroeconomic modeling and about the functioning of elaborate overlapping generation models and the link between the real economy, financial sector, and pension system. The analysis successfully conveys the importance of paying attention to the upcoming demographic transition and helps understand how pay-as-you-go pension systems should be remodeled to deal with this transition. The book is a worthy contribution to the literature on pensions and demographic transitions. 